\title{
Evaluation of the Effectiveness of Group Assertiveness Program on Increasing the Social Skills of Autistic Students
}

\author{
Akram Hafezi ${ }^{1}$, Zohreh Majd ${ }^{2}$, Fatemeh Sedighi ${ }^{3,}$ * \\ ${ }^{1}$ Curriculum Planning, Farhangian University, Tehran, Iran \\ ${ }^{2}$ Educational Management, Faculty of Educational Sciences and Psychology, Shiraz University, Shiraz, Iran \\ ${ }^{3}$ Clinical Psychology, School of Medicine, Islamic Azad University, Zahedan Branch, Zahedan, Iran
}

\section{Email address:}

fa.sedighi76@gmail.com (F. Sedighi)

${ }^{*}$ Corresponding author

\section{To cite this article:}

Akram Hafezi, Zohreh Majd, Fatemeh Sedighi. Evaluation of the Effectiveness of Group Assertiveness Program on Increasing the Social Skills of Autistic Students. International Journal of Education, Culture and Society Vol. 6, No. 4, 2021, pp. 112-119. doi: $10.11648 /$ j.ijecs.20210604.13

Received: June 11, 2021; Accepted: July 10, 2021; Published: July 27, 2021

\begin{abstract}
The aim of this study was to investigate the effectiveness of group assertiveness program on increasing the level of social skills of autism students. In this study, first using the social skills test (Ahmadi-Nourani, 1997) students with skills Low social, those who received a score lower than 100 were identified. These individuals were selected as a sample and then randomly divided into experimental and control groups. The statistical sample of this study included 30 autism students who were randomly selected. The experimental and control groups were divided into two groups of 15 people. Then, the group training program was taught to the experimental group in 10 sessions. After this training, social skills tests were performed on both groups. Finally, the data were analyzed. According to the results, the experimental group, children who were trained in the courage program, performed better than the control group in the social skills test. That is, the group courage program was effective in increasing the social skills and non-verbal social relationships of autistic students. It is therefore suggested that the direction Increase self-expression and improve the social skills of students with autism. Use a group learning program.
\end{abstract}

Keywords: Group Daring, Assertiveness, Social Skills, Social Skills Test, Autism

\section{Introduction}

Children have little contact with their peers, miss opportunities that enable social, cognitive, and moral skills. They are also socially isolated, prone to depression, and have fewer school functions. In daring training, the person is taught how to show behavior based on courage and boldness. The person tries to discover and define the problem, pursue the desired goals (always with courageous behavior), repeat the role. Inverting the role and gradually and consistently presenting desirable behaviors teaches appropriate methods based on courage to express one's desires [1]. Bold behavior with positive self-concept, self-esteem, dominance, selfsufficiency and Self-confidence is correlated and assertive behaviors are deterrent and avoidance and have a high and positive correlation with fears, social anxiety and types of internal aggression [1]. Courage training is a structured intervention method that is used to improve the effectiveness of social relationships. This method is also used to treat anxiety disorders and morbid fears in children, adolescents and adults. This particular approach is only It is not used for people with clinical problems, but it is widely used in the business world, especially in sales and management [2].

Autism is a growth disorder that occurs in the first three years. Life appears. It affects the child's brain, disrupts social behaviors and communication skills. People with autism have commonalities in communication, social and sensory deficits, but also in severity, number of symptoms or age. Its onset is different. Autism is a neurological disorder that affects the growth and function of the brain. Autism is a spectral disorder. In other words, its symptoms and features can be seen in a wide range of combinations, from mild to severe. 
Two children with the same diagnosis, they can act very differently from each other and have different skills. The profile of performance observed in the academic assessments of autistic people is similar to that obtained in the intelligence tests. When entering school, their mechanical and functional abilities are intact and flawless. The ability to use abstract, conceptual, and semantic concepts is flawed [3]. Puberty and adolescence are important for adolescents with highfunctioning autism spectrum disorder. These adolescents need more education than their peers to understand puberty and the changes that come with it. Lack of parents' awareness of how to deal with adolescents, lack of strengthening social skills and not providing sufficient information to them, can cause various problems, including the creation or increase of behavioral and adaptive problems. It seems that educating mothers and adolescents based on an organized program can play an important role in reducing behavioral problems and increasing adaptive skills in adolescence and adolescence. Adolescents with autism spectrum disorders need more education to provide appropriate behavior due to the limitations they face, so it is important to plan educational programs for this group of adolescents and families [4].

The characteristics of children with autism are summarized as follows: insisting on uniformity and resistance to change, having difficulty expressing their needs, and Instead of using words, they use gestures, repetition of words, inappropriate laughter, unnecessary crying, showing stress and unexplained anxiety, preferring to be alone, aggression in autism, difficulty communicating with others, They do not like to be hugged or if someone hugs them, they do not have eye contact or they are very small, they cannot learn anything with the usual educational methods. Early studies of people with autism indicate a number of outstanding abilities in these individuals that the term autistic scientists, which is equivalent to the term stupid scientists in the context of mental retardation, refers to this group [5]. Low-spirited children do not ask questions because they are shy, they do not answer questions, and as a result they appear to be more educationally retarded than they really are. They are also socially empowered to communicate better, such as looking at The do not have the eyes of the other person and the evaluation of others. Children who are shy and daring, their sense of self-worth is minimized and their motivation to do things decreases, so they are constantly faced with failures and face Bitter and unsuccessful experiences cause a lack of courage in these children [6].

Bold behavior is an appropriate expression of emotions and feelings (except anxiety) towards another. The existence of such behavior causes a person to express his feelings and emotions in front of the behavior of others, without fear and in the right way. The performer will show less excitement [7]. Contrary to a number of behavioral problems, assessing assertiveness is more or less easy. Existence refers to appropriate social behaviors that are effective in removing obstacles that interfere with achieving one's goals. The meaning of such a definition is that one can truly express one's positive or negative feelings. Lazarus (1971) calls this ability emotional freedom. Learning means training to express oneself in such a way that one can easily express one's positive or negative feelings and express oneself. Learning about things like: rejecting a request, articulating your limitations, asking, taking the initiative at the beginning of a social approach, accepting it Reciprocity is emphasized, acceptance of being different from others [8]. Adolescence is not an inherited phenomenon that is passed from parent to child, but parents teach courage to the child in the family. It is transmitted to the child through parental anxiety, which means that some parents do not allow their children to acquire the necessary skills due to their perfectionism. Children who become less active gradually lose their sense of self-worth and lose their self-esteem. Their motivation to do things is reduced to a minimum, and this leads to their multiple failures in their social relationships and to the fact that they refuse to socialize with others, and this causes them to lose opportunities to learn social skills. The lack of courage that has been taught to the child at home and through the parents and has gradually made him a lackluster person will certainly be reinforced in the school as well. Dare, although he knows the correct answer to the question, but does not dare to answer it, or when he utters a word or does not understand a part of the lesson, he cannot ask his teacher because of his lack of courage. Some of these children They have a lot of intelligence, but they hide it behind a halo with little courage [6].

The goal of audacity is not to go from one end of the continuum to the other. That is, to become an aggressive person. Neither of these two limits is a sign of appropriate adaptive behavior, that the person is completely passive, has sufficient social skills and confidence. Not self-motivated, or angry or aggressive is not appropriate [9]. Among the other skills that should be given much attention in the autism spectrum are social skills. There are several hypotheses about a deficiency in social skills. Gersham (2008) hypothesized that potential problems may begin with violations of these skills. For example, lack of skills to deal appropriately with others or functional deficiencies that manifest themselves in poorly performing learned skills. Perlmarter (2012) found that students with mild disabilities lack motivation and cognitive abilities to use positive social behaviors. Social skills are the ability to respond to an environment that creates, maintains, and enhances positive effects among individuals [10]. Exceptional children, especially children on the autism spectrum, have many needs, including social and communication skills due to their limitations as well as the dysfunctional education system and lack of parental awareness. These needs are often not met. There is a way to help children with special needs develop their social skills. Group learning is one of the most effective ways to teach how to communicate with others [11]. Heisberg, DutchWebker (2008) believe that Social problems and anxiety, multi-content therapies They are very ideal as a group. They introduce group therapy as a stimulus for anxiety. In the first few sessions, people may simply become anxious. Attending this session as a coping therapy can be helpful and gradually 
Individuals' anxiety is reduced in group sessions. During group sessions, individuals are forced to learn new skills and new ways of coping with anxiety-inducing group situations, and then use these skills in situations outside of group sessions to assess their effectiveness.

Many researches have been done around the subject of research inside and outside the country, some of which are referred to:

The aim of this study [12] was to evaluate the effectiveness of group counseling on assertiveness in reducing depression in high school students in Karaj. For this purpose, out of 698 high school students, 40 people with higher scores were randomly divided into experimental and control groups using Beck Depression Inventory. Then, the group counseling method was performed in 8 sessions of 90 minutes for the experimental groups and the control groups did not receive any intervention. The findings were analyzed using t-test using SPSS software. The results showed that cognitive behavioral group counseling significantly reduced depression.

The aim of this study [12] was to evaluate the effectiveness of group counseling on assertiveness in reducing depression in high school students in Karaj. For this purpose, out of 698 high school students, 40 people with higher scores were randomly divided into experimental and control groups using Beck Depression Inventory. Then, the group counseling method was performed in 8 sessions of 90 minutes for the experimental groups and the control groups did not receive any intervention. Findings were analyzed using t-test using SPSS software. The results showed that cognitive-behavioral group counseling significantly reduced depression.

Ghaffarian (2009) in a pilot study, the positive effect of courage training on academic achievement and social skills of middle school and high school girls in the region has been reported.

Yaghoubi (2006) in his research on high school students has shown that training education through group role is effective in improving social skills.

Nisi and Shahni Yilagh (2001) in an experimental study on first year high school male students have shown that courage training increases assertiveness, self-esteem and mental health and reduces social anxiety.

Mohammadi, Mansour, Ejei, Rasoulzadeh (2002) found that group social training and group training improve social functions and reduce normative behavior disorders in adolescents.

Guttman, Gonz, and Schuler (2008) used a multicultural behavioral program with isolated children, using selfsuspended speech patterns, preparing and teaching social skills, and observed that after treatment, their relationship with His peers rose.

Lent et al. (2002) suffered from high and low anxiety, and showed that the effect of courage training in the experimental groups was greater than the control groups and reduced anxiety and increased courage.

Huizo et al. (2001) showed that the most effective therapeutic trends in social skills are the use of modeling therapies as well as practice and behavioral review in reality.

Given what has been said, people with disabilities are at the same level as other groups in terms of basic life and social skills. Many children and adolescents with autism often fail academically due to lack of courage and assertiveness. Learned helplessness, isolation, isolation, and depression. In other words, children and adolescents with low and daring autism gradually lose their sense of self-worth as a result of which their motivation to do things decreases and therefore suffers. Consecutive failures occur and these failures create in them the belief that they will never be successful people at the social level, so they reduce their efforts and practically do not engage in new experiences. The development of these children and adolescents with bitter and unsuccessful experiences, their daring state continues and increases over time [13].

Children with autism are more prone to mental disorders and compromise They are psychological deficiencies. During learning skills, a child with autism has serious problems in establishing a correct and effective relationship with the environment. Able to receive and understand It is not a complete description of others and educators and cannot express their needs. At this stage, the child seems less intelligent than he is [14]. Social and personality development of individuals in general depends How they relate to others Language is the most important means of communication among ordinary people. A person who has the courage can communicate closely with others, protect himself from the abuse of others, can make decisions and choices freely, and Can express a wide range of positive and negative needs and thoughts to feel guilty and anxious or harm the rights of others [13] A person with autism who has a high level of courage and social skills. Social interactions with others, especially ordinary people, are successful, but the lack of self-expression and lack of adequate social skills is a major barrier for people with autism in social issues and social communication, so improving their daring and social skills is essential. It seems [15]. Because these children have difficulty expressing ideas and beliefs and cannot easily express their feelings and emotions, so they have difficulty in establishing a correct and logical relationship with those around them and gradually move away from society and social relations. Pay. Courage teaches the appropriate social behaviors to express oneself, express emotions, attitudes so that one can easily express oneself in various situations and participate in social relations, and this is self-belief and It boosts self-confidence in him. Such a person recognizes and believes in his abilities and limitations and achieves success in his education and social communication with positive selfbelief and self-concept. Assertiveness training is also a method of intervention designed to enhance interpersonal skills. In fact, in the present study, we extend the training of assertiveness program on the assumption that weakness in social skills is associated with inadequate interpersonal function. In this study, considering the characteristics of daring people with autism and the positive effects that daring can have on such people, the researcher will try to evaluate 
the effects of daring on improving the social skills of daring students with autism. It will show to what extent daring will improve the social skills of these students and Implement a group assertiveness program at the said skill level and listening to autistic students is effective.

\section{Research Method}

In order to answer the research questions, the eclectic method has been used here, ie quantitatively and qualitatively. In the quantitative method, the quasiexperimental method and in the qualitative method, the case study have been used. The research plan is semi-experimental as a preliminary and final test with The control group and the use of random sampling. In this study, the experimental and control group will include male and female students with autism who have low levels of social skills. The independent variable, ie group assertiveness program, during 10 sessions on The experimental group will be applied and the control group will be protected from the influence of such a factor. The statistical population is all students with autism in Tehran. A total of 30 students were randomly selected by available sampling method. In this study, in order to collect information from Ahmadi and Nourani (1997) Social Skills Questionnaire and Daring Training Program. Group used. This questionnaire has 40 questions, which is answered by the 5 point Likert method. This tool has acceptable reliability features, while comparing some scores with a more uniform distribution than its predecessors. This test has a good validity as this test explains between 30 to $35 \%$ of the variance between individuals based on the registration of relationships and social interactions related to verbal and non-verbal social skills. The validity of children's social skills test is usually more than $80 \%$ alpha.

\section{Methods}

After selecting the sample from the statistical population, the samples were randomly divided into two groups of experimental and control. And control, under the same conditions, Ahmadi and Noorani social skills test was performed on both groups. This stage is considered as pretest. After performing the pre-test stage, the experimental group was trained in daring skills in 10 sessions, but the control group they did not receive these trainings and skills. Then, immediately after the end of the daring training sessions, both experimental and control groups were assessed again under the same conditions through social skills questionnaires. The results were analyzed. In the present study, using SPSS software in two descriptive and inferential levels, the obtained data have been analyzed. At the descriptive level, the following statistical indicators have been used while classifying the data: frequency-frequency indices, frequency percentage Density percentage (central tendency indices and dispersion indices (variance), standard deviation, standard error, mean) at the level of inferential statistics were used in proportion to the statistical analysis of multivariate analysis of covariance. We have tried to attribute the observed changes in the post-test to the experimental variable. In fact, the main reason for choosing this method is that this statistical method by comparing the pre-test and post-test results allows us to We can compare pre-test and post-test results and conclude whether this training method has been effective in improving social skills or not.

Findings

The purpose of this study was to evaluate the effectiveness of group assertiveness program on increasing the social skills of autistic students through action research. The findings of the study are as follows:

\section{A. Descriptive analysis}

The present study was performed on a sample size of 30 elementary school students with autism. The subjects were randomly divided into two groups of experimental $(\mathrm{n}=15)$ and control $(\mathrm{n}=15)$.

Histogram of social skills in sample people

Table 1. Frequency distribution of pre-test and post-test social skills.

\begin{tabular}{llll}
\hline \multicolumn{3}{l}{ Frequency distribution after social skills test } \\
\hline Scors & frequently & Percentage & Percentage \\
\hline 1 & 2 & $6 / 7$ & $6 / 7$ \\
2 & 7 & $23 / 3$ & 30 \\
3 & 10 & $33 / 3$ & $63 / 3$ \\
4 & 6 & 20 & $83 / 3$ \\
5 & 5 & $16 / 7$ & 100 \\
Total & 30 & 100 & \\
\hline
\end{tabular}

\begin{tabular}{llll}
\hline \multicolumn{4}{l}{ Frequency distribution of social skills pre-test } \\
\hline Scors & frequently & Percentage & Percentage \\
\hline 1 & 3 & 10 & 10 \\
2 & 4 & $13 / 3$ & $23 / 3$ \\
3 & 15 & 50 & $73 / 3$ \\
4 & 6 & 20 & $93 / 3$ \\
5 & 2 & $6 / 7$ & 100 \\
Total & 30 & 100 & 10 \\
\hline
\end{tabular}

Table 2. Indices of central tendency and dispersion of pre-test scores of social skills.

\begin{tabular}{lll}
\hline Indicators & Group & Group \\
\hline Average & $72 / 6$ & $71 / 07$ \\
Middle & 69 & 71 \\
View & 66 & 73 \\
The standard deviation & $10 / 682$ & $11 / 73$ \\
Variance & $114 / 114$ & $138 / 64$ \\
The first quarter & 45 & 50 \\
The second quarter & 51 & 46 \\
The third quarter & 96 & 96 \\
\hline
\end{tabular}

As can be seen in the table above, the experimental group had an average of $72 / 60$ and a range of 45 , a deviationcriterion of 10/68 and a variance of 114.114 . The control group with a mean of 71/07 and a mean of 71 and a range of 50 had a standard deviation of $11 / 73$ and a variance of $138 / 64$.

As can be seen in the table above, the experimental group had a mean of 90/53 and a median of 91, the amplitude of changes was 44 , the standard deviation was $11 / 13$ and the variance was 123/98. The control group with a mean of $71 / 53$, a median of 70 and a range of changes of 47 had a 
standard deviation of $11 / 19$ and a variance of $125 / 41$.

Table 3. Characteristics of central orientation and dispersion of post-test skills social skills.

\begin{tabular}{lll}
\hline Indicators & Group & Group \\
\hline Average & $90 / 53$ & $71 / 53$ \\
Middle & $91 / 00$ & 70 \\
View & 91 & 74 \\
The standard deviation & $11 / 135$ & $11 / 119$ \\
Variance & $123 / 981$ & $125 / 410$ \\
The first quarter & 44 & 47 \\
The second quarter & 65 & 49 \\
The third quarter & 109 & 96 \\
\hline
\end{tabular}

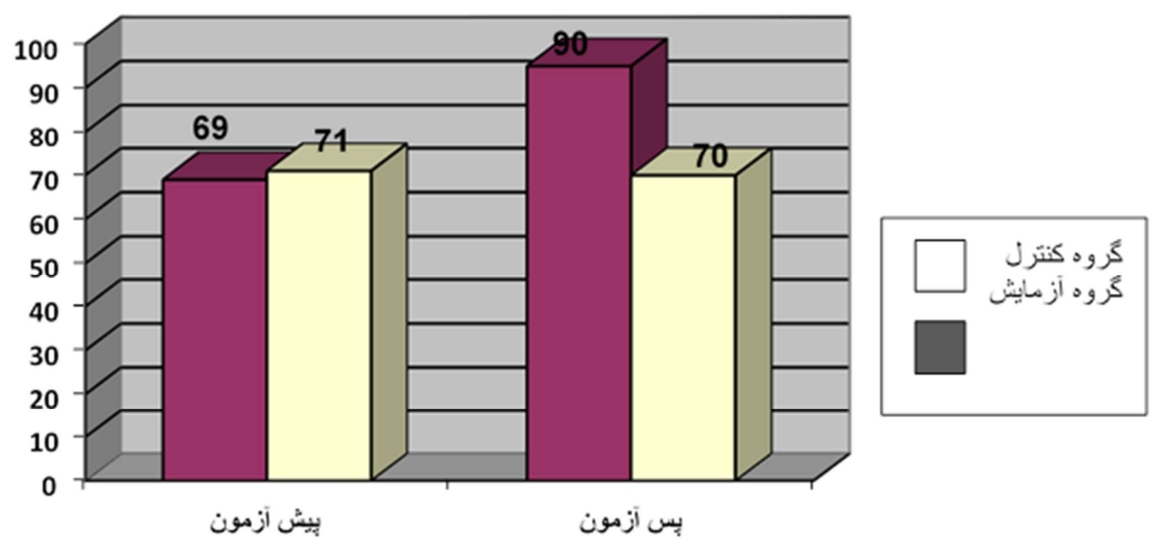

Figure 1. Comparison of social skills in repeated tests between experimental and control groups.

As can be seen in Figure 1, the difference between the pretest and post-test means of social relations in the experimental group is much larger compared to the control group. However, the significance of this difference is a matter that must be clarified in the inferential section.

B) Inferential analysis

In this section, using appropriate statistical tests, the inferential review of research hypotheses has been done. In reviewing the pre-test and post-test research design with the control group, two methods are used. The test is subtracted from the post-test scores and the obtained difference scores are obtained according to the experimental groups and independent t-test. Another method is to use analysis of covariance. Adjustments of pre-tests are compared. We have used both methods in our research.

Analysis of covariance
Hypothesis 1: Implementing a group assertiveness program is effective on the social skills of students with autism.

According to the information in the table, the number of people in the experimental and control groups is equal to 15 people. Also, the average pre-test scores of social skills in the experimental group is $72 / 60$ and in the control group is $71 / 07$ and the standard deviation of the scores of the control group is equal. 73.11 But the standard deviation of the experimental group scores was 11/13. Also, the mean scores of the experimental group in social skills were $90 / 53$ and the mean scores of the control group were $71 / 53$ and the standard deviation of the scores of the control group was $11 / 19$. The standard deviation of the experimental group scores was $11 / 13$.

Table 4. Descriptive indicators of the control and experimental group in social skills.

\begin{tabular}{lllll}
\hline & Groups & number & average & standard deviation \\
\hline \multirow{2}{*}{ pre- test } & the experiment & 15 & $72 / 60$ & $10 / 682$ \\
& Witness & 15 & $71 / 07$ & $11 / 732$ \\
\multirow{2}{*}{ Post-test } & the experiment & 15 & $90 / 53$ & $11 / 135$ \\
& Witness & 15 & $71 / 53$ & $11 / 199$ \\
\hline
\end{tabular}

Table 5. Results of post-test analysis of covariance based on social skills pre-test.

\begin{tabular}{llllll}
\hline Source & Total & Degree & average & F & Significance level \\
\hline Model & $6081 / 93$ & 2 & $3040 / 96$ & $701 / 55$ & $0 / 001$ \\
Interaction & $77 / 12$ & 1 & $77 / 12$ & $17 / 79$ & $0 / 0002$ \\
Before & $3374 / 43$ & 1 & $3374 / 43$ & $778 / 49$ & $0 / 001$ \\
group & $2285 / 35$ & 1 & $2285 / 35$ & $527 / 23$ & $0 / 001$ \\
Error & $117 / 03$ & 27 & $4 / 33$ & & \\
Total & $5853 / 94$ & 29 & & & \\
\hline
\end{tabular}


Based on the information in the table above, the sum of squares of variance observed in the model was 6081/93. In separating this sum of squares into its components, we see that $77 / 12$ is due to the effect of pre-test interaction with grouping, $3374 / 43$ is due to pre-test, $2285 / 35$ is due to grouping and finally $117 / 03$ is due to error. The sum of the set of rigors resulting from the pre-test and grouping is equal to 5853/94, which together with the set of errors and interaction explains the total set of rigors of the model. Significant effects in this model are the effect of grouping interaction with the pre-test at the level of 0.001 and the effect of grouping at a significant level of 0.001 and the effect of pre-test at a significant level of 0.001 .
Based on the information in the table above, the average scores of the experimental group and the control group have different scores of $17 / 49$ in the dependent variable. This difference is significant at the level of 0.001 and therefore, it can be said that applications have had a significant effect. In other words, daring education has had a significant effect on the development of social skills or learners.

Calculate the differences using the second method

As mentioned before, in this method, we first subtract the pre-test scores from the post-test scores and then examine the differences using independent t-statistical analysis:

Hypothesis 1: Implementation of group assertiveness program affects the social skills of autism students.

Table 6. Study of the difference between the means of the groups in terms of social skills.

\begin{tabular}{lllllll}
\hline Groups & number & average & standard deviation & Degree & T & Significance \\
\hline the experiment & 15 & $90 / 53$ & $11 / 13$ & 28 & $0 / 600$ \\
Witness & 15 & $71 / 53$ & $11 / 19$ & & \\
\hline
\end{tabular}

Table 7. Investigating the differences between experimental and control groups in social skills.

\begin{tabular}{|c|c|c|c|c|c|c|}
\hline Groups & Number & Average & Standard deviation & $\mathbf{T}$ & Degree & Significance level \\
\hline Experimental group social skills & 15 & $17 / 93$ & $2 / 4918$ & $23 / 23$ & 28 & $0 / 001$ \\
\hline Control group social skills & 15 & $0 / 46$ & $1 / 505$ & $23 / 23$ & 28 & $0 / 001$ \\
\hline
\end{tabular}

Based on the data obtained from t-test, the mean of deviation scores was 0.46 for the control group and 17/93 in the experimental group. Also, the standard deviation of the control group was 50.1 and the standard deviation of the experimental group was $2 / 49$. Based on this, the value of $t$ was equal to $23 / 23$ which was significant with a degree of freedom of 28 and a significance level of 0.001 . This shows that there is a significant difference between the two groups of control and experiment in terms of the variable of deviations of the post-test score from the pre-test, in other words, the exercise of courage was associated with success and had a significant effect.

Hypothesis 2: The implementation of group assertiveness program is effective on the level of communication skills of autistic students.

To test this sub-hypothesis, we first examine the descriptive findings related to the dialogue skills variable in the following table:

Table 8. Descriptive indicators of the control and experimental groups in the Dialogue and speaking skills variable.

\begin{tabular}{lllll}
\hline & Groups & number & average & standard deviation \\
\hline \multirow{2}{*}{ pre- test } & the experiment & 15 & $6 / 00$ \\
& Witness & 15 & $5 / 53$ & $1 / 00$ \\
Post-test & the experiment & 15 & $6 / 86$ & $0 / 74$ \\
& Witness & 15 & $5 / 53$ & $0 / 51$ \\
\hline
\end{tabular}

According to the information in the table, the number of people in the experimental and control groups is equal to 15 people. Also, the average pre-test scores of Conversation skills in the experimental group is $6 / 00$ and in the control group is $5 / 53$ and the standard deviation of the scores of the control group is equal $0 / 74$. But the standard deviation of the experimental group scores was $1 / 00$. Also, the mean scores of the experimental group in Conversation skills were 6/68 and the mean scores of the control group were $5 / 53$ and the standard deviation of the scores of the control group was $0 / 74$. The standard deviation of the experimental group scores was $0 / 71$.

Table 9. Results of post-test analysis of covariance based on skills pre-test Dialogue and speaking.

\begin{tabular}{|c|c|c|c|c|c|}
\hline Source & Total & Degree & average & $\mathbf{F}$ & Significance level \\
\hline Model & $17 / 69$ & 2 & $8 / 84$ & $33 / 6$ & $0 / 001$ \\
\hline Interaction & $8 / 37$ & 1 & $8 / 37$ & $31 / 79$ & $0 / 001$ \\
\hline Before & $4 / 35$ & 1 & $4 / 35$ & $16 / 55$ & $0 / 001$ \\
\hline group & $8 / 81$ & 1 & $8 / 81$ & $33 / 49$ & $0 / 001$ \\
\hline Error & $7 / 1$ & 27 & $0 / 263$ & & \\
\hline Total & $24 / 8$ & 29 & & & \\
\hline
\end{tabular}

Based on the information in the table above, the sum of squares of variance observed in the model was $24 / 80$. In 
separating this sum of squares into its components, we see that $8 / 37$ is due to the effect of pre-test interaction with grouping, $4 / 35$ is due to pre-test, $8 / 81$ is due to grouping and finally $7 / 1$ is due to error. The sum of the set of rigors resulting from the pretest and grouping is equal to $13 / 1$, which together with the set of errors and interaction explains the total set of rigors of the model. Significant effects in this model are the effect of grouping interaction with the pre-test at the level of 0.001 and the effect of grouping at a significant level of 0.001 and the effect of pre-test at a significant level of 0.001 .

To examine the subject further, we examine the dependent variable (post-test) based on groupings:

Table 10. Investigating the differences between the means of the groups in terms of dialogue skills.

\begin{tabular}{lllllll}
\hline Groups & number & average & standard deviation & Degree & T & Significance \\
\hline the experiment & 15 & $6 / 86$ & $0 / 51$ & 28 & $0 / 001$ \\
Witness & 15 & $5 / 53$ & $0 / 71$ & & \\
\hline
\end{tabular}

Based on the information in the table above, the value of $t$ for the post-test scores of the dialogue variable in the two experimental groups with a degree of freedom of 28 was $5 / 7$, which was significant at the significance level of 0.001 . This shows that assertiveness training has a positive and significant effect on communication skills.

The analysis of the research hypotheses showed that both research hypotheses were confirmed:

Implementing a group assertiveness program affects the social skills of autistic students. This hypothesis was confirmed at a significance level of 0.001 .

Implementing a group assertiveness program affects the level of communication skills of autistic students $(p<0 / 01)$.

\section{Discussion}

In this study, the effectiveness of group assertiveness method on increasing social skills of children with autism with low level of social skills was investigated. The results showed that the implementation of group assertiveness program is effective on the level of social skills of autistic students. The hypothesis was confirmed at the significance level of 0.001 . These findings indicate that daring is an effective method in Increased audacity and self-esteem of autistic students is considered low.

Daring is usually done by assigning homework and weekly planning on the client's activities in the family, workplace and community, as well as Social and communication skills training is combined and during this process to the educational authorities Is given to show daring action in different situations. Courage is used to deal effectively with situations and to eliminate anxiety in the face of adversity [16].

Possible reasons for the increase in courage may be due to this Participating in bold programs has helped daring students Is To achieve the necessary self-knowledge and bold behaviors in interactive situations with Practice others realistically and naturally And to use. As it was observed, the intervention program (daring) has an effect on raising the self-esteem of low-courage students. increase the self-esteem of daring students can be attributed to their participation in daring programs. Because students are aware of their feelings and emotions in the daring program and the way to deal with criticism, the way of expressing dissatisfaction, the way of refusing and not accepting an offer or a request, defining the desirable behaviors of others and participating in group affairs Have learned and practiced [17]. Courage training is a structured intervention method that is used to improve the effectiveness of social relationships. This method is also used to treat anxiety disorders and morbid fears in children, adolescents and adults. This particular approach is only It is not used for people who have clinical problems, but it is also widely used in the world of business, especially in the fields of sales and management [19]. Exceptional children, especially children with autism, have many needs, including the need for social and communication skills due to their limitations as well as the dysfunctional education system and lack of parental awareness. These needs are often not met. There are many ways to help children with special needs to develop their social skills. Group learning is one of the most effective ways to teach how to communicate with others [11] Research has shown that implementing a learning program it can improve the social skills of students with autism.

\section{Conclusion}

From the summary of research records that have been mentioned, it can be concluded that many problems of children, especially children with autism, in the field of social skills as well as in establishing social communication in the form of Verbal and non-verbal are the main problems of these children in the field of expression and expression in such a way that they can show their abilities and capabilities. Research information shows that courage training has a positive and significant effect on skills. At the end of the study, the following behavioral changes were observed in the children in the experimental group: The child had less difficulty speaking and was able to express himself, it was easier for him to say something in general, than before. He did not disobey his teacher, the child did not interrupt others, he was not shy and do not shy away from group work and love to take the lead in making friends with others. Many factors may jeopardize the internal and external credibility of the research. Therefore, researchers are doing their best to remove these barriers and increase the credibility of their research. In the present study, we also faced limitations in each area, including: due to the limitations of society. There was no possibility to control and determine the effects of other disturbing factors that may affect the social skills of children with autism; lack of research resources to complete research records and explain the 
findings; time constraints on research and data collection and the limitations of sampling so that multidimensional and multidimensional sampling can lead to better results. According to the research findings, it is suggested that: Autism educators to promote assertiveness skills in their learners in order to be indirectly involved in developing their social skills and parents to develop assertive skills according to the effect of these skills on Relationships and social skills in students.

\section{References}

[1] Saatchi. Mahmood. (2006). Counseling and psychotherapy (theories and strategies). Tehran: Editing Publications.

[2] Nisi, Abdul Kazem, summer city, Manijeh. (2000). The effect of assertiveness training on assertiveness, self-esteem, social anxiety and mental health, students, socially disturbed boys, high school, city, Ahvaz. Journal of Psychological Achievements, 8 (1), 11-30. doi: 10.22055 / psy.2001.16464.

[3] Ameri Siahoui, Hamidreza and Mashhadi Fath Ali, Hana, 2014, Educational spaces for autistic children from the perspective of environmental psychology, Second National Conference on Architecture, Restoration, Urban Planning and Sustainable Environment, Hamedan.

[4] Akrami L, Mokhtar M, Faramarzi S, Abedi A. The Effect of Behavioral Management and Social Skills Training Program on Behavioral and Adaptive Problems of Male Adolescents with High-Functioning Autism. jrehab. 2019; 20 (4): 322339URL: $\quad$ http://rehabilitationj.uswr.ac.ir/article-1-2442fa.html.

[5] Rahimian Bogar, Ishaq, Shara, Hossein, Habibi Asgarabad, Mojtaba, Besharat, Mohammad Ali. (2007). Investigating the effect of assertiveness practices on social adjustment. Educational Innovations, 6 (4), 29-54.

[6] Afrooz, Gholam Ali - Psychology and Education of Exceptional Children, 1998, University of Tehran Press. Iran.

[7] Noorullah-Mansour, Mahmoud-Ejei, Javad Rasoulzadeh, Kazem. 2002. Investigating the therapeutic effect of social empowerment training on Normative Behavior Disorder in Adolescents. Journal of Psychology 24. 6 (4).1-10.

[8] Lotfi Kashani, Farah, Vaziri, Shahram (2007). Clinical psychology of the child. Tehran: Arasbaran Publications.

[9] Rahimi, Jafar-Haghighi, Jamal-Mehrabizadeh, Mahnaz-
Bashlideh, Kiomars. (2006). Investigating the effect of courage on Social skills, social anxiety and assertiveness in first year high school male students in Ahvaz. Magazine Educational Sciences and Psychology, Shahid Chamran University of Ahvaz, No. 1, p. 111-127.

[10] Aghaei, Malekpour and Ajami (2003). The effect of assertiveness training on self-expression behavior of elementary school students Shahre Nain Master Thesis in Educational Psychology, Faculty of Educational Sciences and Psychology.

[11] Atler, R. Hardman, M, 2003, Your perfect right; a guide for assertive Living, Impact. sun luis opispo. California.

[12] Zare Benadokouki, Ezzat, 2014, Evaluation of the effectiveness of cognitive-behavioral group counseling in expressing depression in adolescents working in high school in District 3 of Karaj, International Conference on Behavioral Sciences and Social Studies, Tehran.

[13] Nouri, Mohammad Ali, 2007. Master's thesis review and comparison of the efficiency of the daring method and A Courageous Method with Cognitive Reconstruction on Some Socially Anxious Adolescents in Tehran, Institute Tehran Psychiatry.

[14] Esmaeili M. The Effectiveness of Social Skills Training by Cognitive-Behavioral Group in the Increase of Girls' SelfEsteem and Assertiveness with Addicted Parents. etiadpajohi. 2011; 4 (16): 41-56.

[15] Farazi, Tahereh and Zare Benadkouki, Ezzat, 2014, Evaluation of the effectiveness of group counseling for daring assertiveness in cognitive-behavioral method in improving depression of female adolescents studying in high school in District 3 of Karaj, 3rd National Conference on Mental Health, Quchan.

[16] Deletmar, R., \& Mcnamura, J. R. (2007). The social impact of assertivness. Jurnal of Behavior modification, 149-158.

[17] Arendel \& senderman \& hogman \& pikerzgel. G. B. (2004). Social Skills Intervention with learning disable childrek. Selecting Skils 8 Implementing Training. Journal of Clinical Child psychology 8.234.

[18] Delavar, Ali. Research methods in psychology and educational sciences. 2006. Payame Noor University Press. Tehran. Iran.

[19] Naderi, Ezatullah, Saif Naraghi, Maryam. 2007. Research Methods in Humanities, Tehran, Badr Publishing: Tehran. Iran. 